\title{
Using the National Cancer Database to create a scoring system that identifies patients with early-stage esophageal cancer at risk for nodal metastases
}

\author{
Benny Weksler, MBA, MD, ${ }^{\mathrm{a}}$ Kevin F. Kennedy, MS, ${ }^{\mathrm{b}}$ and Jennifer L. Sullivan, $\mathrm{MD}^{\mathrm{a}}$
}

\section{ABSTRACT}

Objectives: Endoscopic resection is gaining popularity as a treatment for earlystage esophageal adenocarcinoma, particularly for T1a tumors. The goal of this study was to create a scoring system to reflect the risk of nodal metastases in early-stage esophageal adenocarcinoma to be used after endoscopic resection to better individualize treatment.

Methods: The National Cancer Database was queried for patients with T1a or T1b esophageal adenocarcinoma who underwent esophagectomy. We identified variables affecting nodal metastases using multivariable logistic regression, which we then used to create a scoring system. We stratified the model for T1a or T1b tumors, tested model discrimination, and validated the models by refitting in 1000 bootstrap samples. C-statistics greater than 0.7 were considered relevant.

Results: We identified 1283 patients with T1a or T1b tumors; 146 had nodal metastases $(11.4 \%)$. Tumor category (pT1a vs pT1b), grade, and size and the presence of angiolymphatic invasion significantly affected the risk of nodal metastases. We assigned points to each variable and added them to get a risk score. In patients with T1a tumors, less than $3 \%$ of patients with a risk score of 3 or less had nodal metastases, whereas $16.1 \%$ of patients with a risk score of 5 or greater had nodal metastases. In patients with T1b tumors, less than $5 \%$ of patients with a risk score of 2 or less had nodal metastases, whereas $41 \%$ of patients with a score of 6 or greater had nodal metastases (c-statistic $=0.805)$.

Conclusions: The proposed scoring system seems to be useful in discriminating risk of nodal metastases in patients with $\mathrm{T} 1 \mathrm{a}$ or $\mathrm{T} 1 \mathrm{~b}$ esophageal adenocarcinoma and may be useful in directing patients who received endoscopic resection to esophagectomy or careful follow-up. (J Thorac Cardiovasc Surg 2017;154:1787-93)

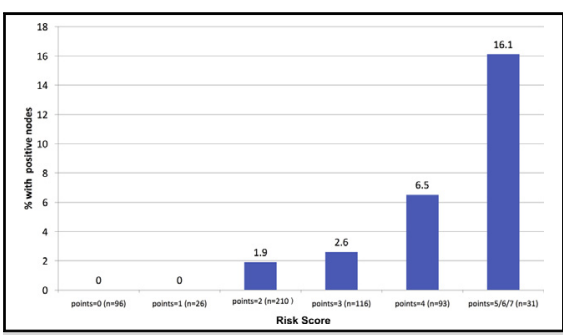

Risk of nodal metastases in patients with T1a EAC.

Central Message

A scoring system was generated to quantitate the risk of nodal metastasis in T1 esophageal tumors that may be useful in guiding patients to esophagectomy or follow-up after endoscopic resection based on this risk score.

\section{Perspective}

Although endoscopic resection is rapidly becoming the standard of care for early-stage esophageal cancer, patients with a high risk of nodal metastasis may be better treated with esophagectomy. We created a scoring system that reflects the risk of nodal metastases and may be useful in appropriately directing patients with $\mathrm{T} 1$ tumors to esophagectomy or follow-up after endoscopic resection.

See Editorial Commentary page 1794.

See Editorial page 1785 .
The incidence of nodal metastases in patients with esophageal tumors that superficially invade the esophagus ( $T$

\footnotetext{
From the a Division of Thoracic Surgery, Department of Surgery, University of Tennessee Health Science Center, Memphis, Tenn; and ${ }^{\mathrm{b}}$ Department of Biostatistics, St Lukes Health System, Mid America Heart Institute, Kansas City, Mo.

Read at the 97th Annual Meeting of The American Association for Thoracic Surgery, Boston, Massachusetts, April 29-May 3, 2017.

Received for publication April 24, 2017; revisions received July 8, 2017; accepted for publication July 16, 2017; available ahead of print Sept 1, 2017.

Address for reprints: Benny Weksler, MBA, MD, Division of Thoracic Surgery, University of Tennessee Health Science Center, 1325 Eastmoreland Ave, Suite 460, Memphis, TN 38104 (E-mail: bweksler@uthsc.edu). $0022-5223 / \$ 36.00$

Copyright (c) 2017 by The American Association for Thoracic Surgery http://dx.doi.org/10.1016/j.jtcvs.2017.07.036
}

category pT1a and pT1b) varies from $10 \%$ to $15 \%$. $^{1,2}$ The risk of nodal metastases in patients with $\mathrm{T} 1$ esophageal adenocarcinoma (EAC) increases with depth of invasion, poorly differentiated tumors, increasing size, and angiolymphatic invasion. ${ }^{3-7}$ Nodal metastases are the most important determinant of long-term survival in patients with superficially invasive EAC. ${ }^{5,8}$

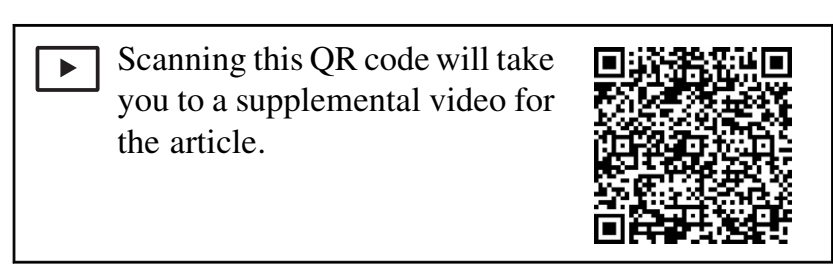




\section{Abbreviations and Acronyms \\ CI = confidence interval \\ EAC $=$ esophageal adenocarcinoma \\ LVI = lymphovascular invasion \\ $\mathrm{NCDB}=$ National Cancer Database \\ $\mathrm{OR}=$ odds ratio}

EACs limited to the mucosa (T1a) are increasingly being treated with endoscopic resection, and survival after endoscopic resection of T1a tumors compares favorably with survival after esophagectomy. ${ }^{9}$ Some practitioners have extended the indications of endoscopic resection to patients with $\mathrm{T} 1 \mathrm{~b}$ tumors with superficial invasion of the submucosa (sm1), with encouraging results. ${ }^{10}$ Clinical staging of T1 EAC is difficult, and endoscopic ultrasound shows a concordance of only $65 \%$ in T1 esophageal carcinoma. ${ }^{11}$ Many authors have recommended endoscopic resection as a staging tool for patients with clinical T1 EAC. ${ }^{12,13}$ For patients with an established diagnosis of $\mathrm{T} 1 \mathrm{a}$ or $\mathrm{T} 1 \mathrm{~b}$ adenocarcinoma after endoscopic resection, multiple authors have devised a scoring system or risk stratification for nodal metastases based on known risk factors. ${ }^{6,14,15}$ These studies were based on a relatively small number of patients, and the largest cohort had 258 patients.

The National Cancer Database (NCDB) collects data from more than 1500 facilities and includes $70 \%$ of all new cancer diagnosis in the United States. ${ }^{16}$ The NCDB has data points for all factors previously associated with a high risk of nodal metastases in patients with EAC. The aim of this study was to create a simple scoring system that can assess the risk of nodal metastases in patients with $\mathrm{T} 1 \mathrm{EAC}$ using this large national database.

\section{MATERIALS AND METHODS}

The NCDB was queried for all patients from 2010 to 2013 who underwent esophagectomy with pathologically confirmed T1a or T1b EAC. Patients were excluded if they received preoperative chemotherapy or radiation therapy, if they had metastases at diagnosis, and if data on $\mathrm{T}$ status or $\mathrm{N}$ status were incomplete. From the participant user files provided by the NCDB, we extracted basic patient demographics, pathologic information, including tumor category, tumor grade, presence of angiolymphatic invasion, number of lymph nodes examined, number of lymph nodes positive for metastases, and any neoadjuvant therapy received by the patient. The NCDB categorizes tumor grade as well as differentiated, moderately differentiated, poorly differentiated, and anaplastic. We combined poorly differentiated and anaplastic into 1 category of poorly differentiated tumors. The NCDB data are completely deidentified; therefore, this study was deemed exempt from approval and informed consent by the Institutional Review Board of the University of Tennessee Health Science Center.

\section{Statistical Analysis}

Data are represented as mean \pm standard deviation or median and interquartile range for continuous variables and as $\mathrm{n}(\%)$ for categoric variables. Unadjusted differences between positive and negative nodes were tested with Student $t$ test and chi-square analysis, where appropriate. Missing data for candidate variables were substituted using multiple imputation methods with sequential regression using IVware software. ${ }^{17}$ The association between tumor size and positive node status also was evaluated as a continuous variable by means of spline regression, using methods as described by Desquilbet and Mariotti. ${ }^{18}$ For this analysis, restricted cubic spline functions were used in the adjusted logistic regression model relating positive node status to natural tumor size to identify the shape of the curve and to test the hypothesis of nonlinearity of this relationship. Using this functional relationship and the Youden index, ${ }^{19}$ we created 3 categories for tumor size: less than $15 \mathrm{~mm}, 15$ to $25 \mathrm{~mm}$, and greater than $25 \mathrm{~mm}$.

To identify independent predictors of positive nodes, we developed a multivariable logistic regression model with the preidentified variables: age, sex, T status, tumor differentiation, tumor size, Charlson comorbidity score, academic institution, and lymphovascular invasion (LVI). Model discrimination was tested with the c-statistic.

Next, we created a point-scoring system using the most prognostic variables for positive nodal status as determined by the beta weights of the variables. ${ }^{20}$ We intentionally did not give a weight to tumor status (T1a/T1b) because we used this variable for stratification. We then graphically assessed the ability of the point system to discriminate between positive and negative nodal status, and computed the c-statistic using only the point system.

Finally, after fitting the model in the entire dataset, we conducted internal validation by refitting the model in 1000 bootstrap samples with replacement. This method of model validation has been found to have lower variability and lower bias potential compared with traditional splitsample validation and k-fold cross-validation. ${ }^{21}$ All measures of model performance were corrected for optimism and a calculated "shrinkage" factor derived from the calibration slope. This analysis led to minimal adjustments to the full model (data not shown).

\section{RESULTS}

We identified 1283 patients with T1a or T1b tumors; 146 had nodal metastases $(11.4 \%)$. There were 572 patients with T1a tumors $(44.6 \%)$ and 711 patients with $\mathrm{T} 1 \mathrm{~b}$ tumors $(55.4 \%)$ (Table 1$)$. The most frequently missing variables in the dataset were tumor size (missing in 18\%), tumor grade (missing in 13\%), and angio-LVI (missing in 16\%). Patients with T1a tumors (18/572) had a $3.1 \%$ incidence of nodal metastases, and patients with T1b tumors (128/711) had an $18 \%$ incidence of nodal metastases. The median age for the full cohort was 65 (interquartile range, 59-71), and 1095 were male $(85.3 \%)$. In multivariable analysis, tumor category (pT1a vs pT1b; odds ratio [OR], 3.45; 95\% confidence interval $[\mathrm{CI}], 2.47-4.81 ; P<.001)$, tumor differentiation (moderately differentiated vs well differentiated; OR, 4.39 ; $95 \%$ CI, 1.55-12.42; $P=.006$; poorly differentiated vs well differentiated; OR, 6.69; 95\% CI, 2.33-19.18; $P<.001)$, tumor size $(15-25 \mathrm{~mm}$ vs $<15 \mathrm{~mm}$; OR, 2.07; $95 \%$ CI, $1.21-3.53 ; P=.008 ;>25 \mathrm{~mm}$ vs $<15 \mathrm{~mm}$; OR, 2.98; 95\% CI, 1.82-4.90; $P<.001)$, and the presence of LVI $(P<.001)$ were identified as significantly affecting the risk of nodal metastases (Figure 1). On the basis of our multivariable analysis, we assigned points to each variable to create a scoring system (Table 2) and then added the points to get the patients' risk scores (Figures 2 and 3).

In patients with T1a tumors, the majority (448/572, $78.3 \%$ ) had a risk score of 3 or less and had a risk of nodal metastases less than $3 \%$. There were 93 patients $(93 / 572$, 
TABLE 1. Patient characteristics

\begin{tabular}{|c|c|c|c|c|}
\hline & $\begin{array}{l}\text { Full cohort } \\
(n=1283)\end{array}$ & $\begin{array}{c}\text { T1a } \\
(\mathrm{n}=\mathbf{5 7 2})\end{array}$ & $\begin{array}{c}\text { T1b } \\
(n=711)\end{array}$ & $P$ value \\
\hline Age, y, median (IQR) & $65(59-71)$ & $64(58-70)$ & $66(60-72)$ & $<.001$ \\
\hline Male sex, n (\%) & $1095(85.3)$ & $477(83.4)$ & $618(86.9)$ & .075 \\
\hline White race, $\mathrm{n}(\%)$ & $1233(97.1)$ & $551(97.2)$ & $682(97.0)$ & .757 \\
\hline Academic institution, $\mathrm{n}(\%)$ & $820(64.5)$ & $383(67.5)$ & $437(62.0)$ & .039 \\
\hline $\begin{array}{l}\text { Charlson comorbidity score, } \mathrm{n}(\%) \\
0 \\
1 \\
>1\end{array}$ & $\begin{array}{l}812(63.3) \\
359(28.0) \\
112(8.7)\end{array}$ & $\begin{array}{c}367(64.2) \\
166(29.0) \\
39(6.8)\end{array}$ & $\begin{array}{r}445(62.6) \\
193(27.1) \\
73(10.3)\end{array}$ & .089 \\
\hline $\begin{array}{l}\text { Tumor grade } \\
\text { Well differentiated } \\
\text { Moderately differentiated } \\
\text { Poorly differentiated }\end{array}$ & $\begin{array}{l}281(21.9 \%) \\
635(49.5 \%) \\
367(28.6 \%)\end{array}$ & $\begin{array}{l}180(31.5 \%) \\
291(50.9 \%) \\
101(17.6 \%)\end{array}$ & $\begin{array}{l}101(14.2 \%) \\
344(48.4 \%) \\
266(37.4 \%)\end{array}$ & $<.001$ \\
\hline Angiolymphatic invasion, $\mathrm{n}(\%)$ & $203(15.8)$ & $42(7.3)$ & $161(22.6)$ & $<.001$ \\
\hline Tumor size, $\mathrm{mm} \pm \mathrm{SD}$ & $16.5 \pm 14.6$ & $12.2 \pm 13.0$ & $19.9 \pm 14.9$ & $<.001$ \\
\hline $\begin{array}{l}\text { Tumor size, } \mathrm{n}(\%) \\
\quad<15 \mathrm{~mm} \\
15-25 \mathrm{~mm} \\
>25 \mathrm{~mm}\end{array}$ & $\begin{array}{l}691(53.9) \\
286(22.3) \\
306(23.9)\end{array}$ & $\begin{array}{r}399(69.8) \\
94(16.4) \\
79(13.8)\end{array}$ & $\begin{array}{l}292(41.1) \\
192(27.0) \\
227(31.9)\end{array}$ & $<.001$ \\
\hline Nodal metastases, n (\%) & $146(11.4)$ & $18(3.1)$ & $128(18.0)$ & $<.001$ \\
\hline Lymph nodes sampled, median (IQR) & $14(9-21)$ & $14(8-21)$ & $15(9-22)$ & .003 \\
\hline Incomplete resection $(\mathrm{R} 1 / 2), \mathrm{n}(\%)$ & $16(1.2)$ & $1(0.2)$ & $15(2.1)$ & .001 \\
\hline $\begin{array}{l}\text { Mortality, n (\%)* } \\
\text { 30-d } \\
90-\mathrm{d}\end{array}$ & $\begin{array}{l}28(2.8) \\
46(4.6)\end{array}$ & $\begin{array}{l}11(2.5) \\
15(3.4)\end{array}$ & $\begin{array}{l}17(3.1) \\
31(5.6)\end{array}$ & $\begin{array}{l}.570 \\
.095\end{array}$ \\
\hline
\end{tabular}

$I Q R$, Interquartile range; $S D$, standard deviation. *Mortality only available for cases between 2010 and 2012.

$16.3 \%$ ) with a score greater than 4 , and those patients had a $6.5 \%$ risk of nodal metastases. In patients with T1a tumors with a score greater than $5(31 / 572,5.4 \%)$, the risk of nodal metastases was greater than $15 \%$. A minority of patients with T1b tumors had a risk score of 1 or less $(72 / 711$, $10.1 \%$ ) and a risk of nodal metastases of less than $5 \%$. Patients with $\mathrm{T} 1 \mathrm{~b}$ tumors and scores 2 or greater had an increasing risk of nodal metastases, ranging from $5.7 \%$ in patients with a score of 2 to greater than $40 \%$ in patients with scores greater than 5 . The model c-statistic was 0.805 . The c-statistic was 0.830 for the T1a point system and 0.775 for the T1b point system. A bootstrap validation cohort did not demonstrate a significant change in the fitness of the model (c-statistic $=0.800)$ or the strength of the predictor variable.

\section{DISCUSSION}

By using the NCDB, we created a simple scoring system that predicts the risk of nodal metastases in patients with T1a or T1b EAC. Our scoring system identified a small population of patients with T1a tumors $(5.4 \%$ of all T1a patients) with a high risk of nodal metastases $(>15 \%$ in patient with scores $>5$ ) and a small population of patients with $\mathrm{T} 1 \mathrm{~b}$ tumors $(10.1 \%$ of $\mathrm{T} 1 \mathrm{~b}$ patients) with a very low risk of nodal metastases $(<5 \%)$. This system may assist practitioners in selecting patients with high-risk T1a tumors for treatment with esophagectomy and patients with lowrisk T1b tumors for follow-up only, after endoscopic resection of T1 EAC. There was also a group of patients with $\mathrm{T} 1 \mathrm{~b}$ tumors (score $>5$ ) with a very high risk of nodal metastases $(>40 \%)$, and these are potentially patients grouped in stage IIB or IIIA. Consideration should be given to neoadjuvant therapy for these patients.

Endoscopic resection has become the standard of care for patients with T1a EACs, ${ }^{22}$ and some authors have been suggesting treatment with endoscopic resection for patients with T1b tumors and superficial invasion of the submucosa (sm1). ${ }^{10}$ It is interesting that although some authors found that superficial invasion into the submucosa was not a risk factor for nodal metastases, ${ }^{3,5}$ others have not been able to demonstrate that superficial invasion into the submucosa conveys little-to-no risk for nodal metastases and recommend esophagectomy for all patients with $\mathrm{T} 1 \mathrm{~b}$ tumors. ${ }^{23,24}$ Our study suggests that there are additional risk predictors that should be considered to determine the best treatment course for patients with $\mathrm{T} 1 \mathrm{~b}$ tumors.

Tumor category (pT1a or pT1b) is likely the most important factor associated with nodal metastases. ${ }^{1,4,6}$ The 


\section{Predictor $(\underline{O R}, \underline{95 \% \mathrm{Cl} \text { confidence interval) }}$}

T1a vs T1b (3.45, 2.47-4.81)

Moderately differentiated vs well differentiated $(3.3,1.9-5.73)$

Poorly differentiated vs well differentiated $(5.37,3.07-9.4)$

Tumor size $15-25 \mathrm{~mm}$ vs $<15 \mathrm{~mm}(1.76,1.25-2.5)$

Tumor size $>25 \mathrm{~mm}$ vs $<15 \mathrm{~mm}(3.21,2.34-4.4)$

Lymph-vascular invasion yes vs no $(3.39,2.17-5.29)$

Male gender $(1,0.68-1.46)$

Age $(0.85,0.75-0.97)$

Charlson co-morbidity score 1 vs $0(0.87,0.65-1.16)$

Charlson co-morbidity score $>1$ vs $0(0.9,0.58-1.41)$

Academic institutions vs others $(1.05,0.81-1.35)$

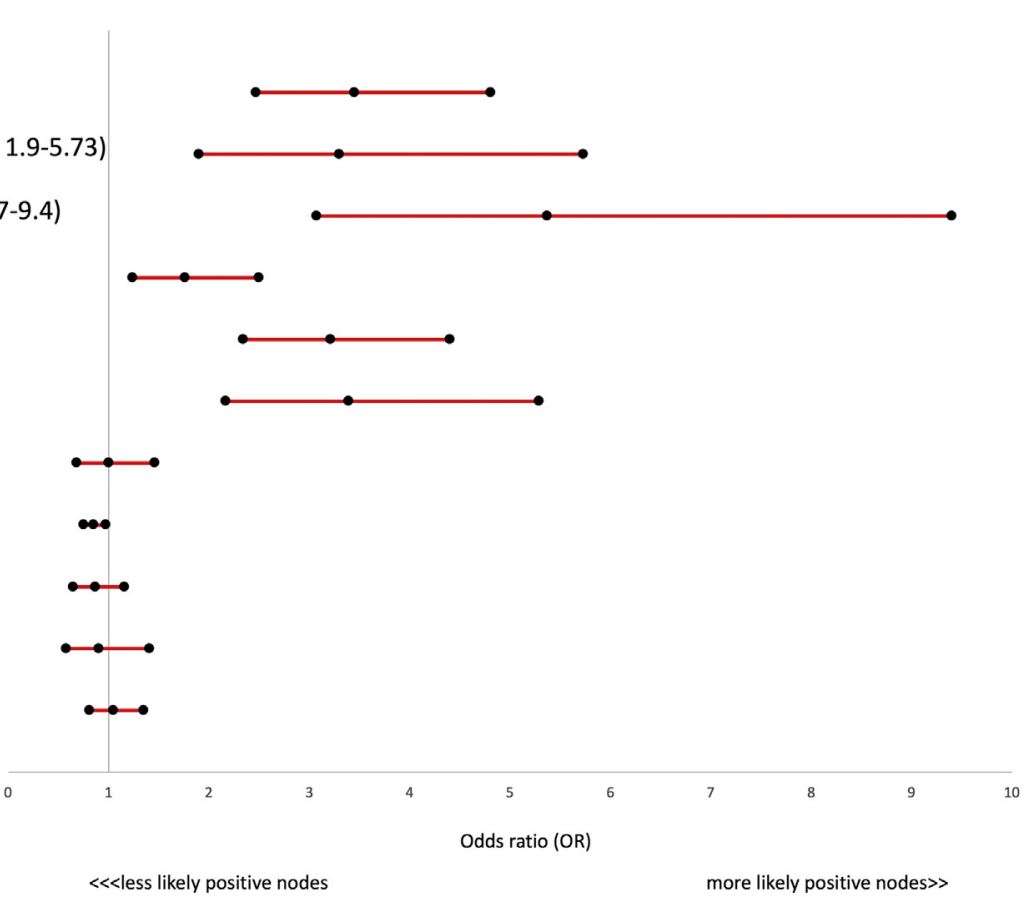

FIGURE 1. Forest plot of predictors for positive lymph nodes. OR, Odds ratio; $C I$, confidence interval.

incidence of nodal metastases in T1a EAC is low, only $0 \%$ to $7 \%$ in several series. ${ }^{1,4,6,14}$ The incidence of nodal metastases in T1a patients in our series was comparable with those results at $3.1 \%$. A previous NCDB study by Merkow and colleagues ${ }^{25}$ found a $5 \%$ incidence of nodal metastases in patients with T1a tumors, a rate slightly higher than ours. It is largely agreed that $\mathrm{T} 1 \mathrm{~b}$ tumors have a significantly higher incidence of nodal metastases than T1a tumors, ranging from $16 \%$ to $27.5 \% .^{5,6,14,15}$ The previous NCDB study reported an incidence of $16.6 \%,{ }^{25}$ similar to the incidence of nodal metastases of $18 \%$ in patients with $\mathrm{T} 1 \mathrm{~b}$ tumors in our study. The differences in the NCDB study of Merkow and colleagues ${ }^{25}$ and ours may

TABLE 2. Points awarded for predictors of lymph node metastasis to calculate risk score

\begin{tabular}{lc}
\hline \multicolumn{1}{c}{ Variable } & Points \\
\hline Grade & \\
Well differentiated & 0 \\
Moderately differentiated & 2 \\
Poorly differentiated & 3 \\
Tumor size & \\
$<15 \mathrm{~mm}$ & 0 \\
$15-25 \mathrm{~mm}$ & 1 \\
$>25 \mathrm{~mm}$ & 2 \\
Angiolymphatic invasion & \\
No & 0 \\
Yes & 2 \\
\hline
\end{tabular}

be because our study only included patients who underwent esophagectomy, whereas Merkow and colleagues included all patients. There is also the possibility of understaging of the $\mathrm{T}$ category and classification of some patients with $\mathrm{T} 1 \mathrm{~b}$ tumors as T1a and or vice versa. ${ }^{26}$ Previous retrospective studies that re-reviewed the pathology in patients with T1 esophageal cancer ${ }^{1,4,6}$ did not provide the number of pathologic diagnosis reversed on reviewed.

To our knowledge, there is 1 other recent attempt to create a scoring system to assess the risk of nodal metastases in patients with T1 EAC. Lee and colleagues ${ }^{14}$ analyzed a cohort of patients with $\mathrm{T} 1$ esophageal cancer who underwent esophagectomy at 5 different institutions. Variables with a prognostic impact in their study were the same as in ours: $\mathrm{T}$ status, tumor differentiation, tumor size, and LVI. The authors assigned scores to each variable, including $\mathrm{T} 1 \mathrm{a}$ and T1b tumor categories. The final model fit was similar to ours with a c-statistic of 0.82 . The main difference between Lee and colleagues' model and ours is that we stratified the score to T1a and T1b tumors. By applying Lee and colleagues' scoring system in our cohort, the scoring systems were equivalent in predicting nodal metastases in patients with T1a tumors (data not shown). However, in patients with T1b tumors, Lee and colleagues' model was less discriminant in patients with a low risk of nodal metastases.

Davison and colleagues ${ }^{6}$ examined records from 210 patients with T1 EAC who underwent esophagectomy at a single institution. The authors did not create a risk score, but 


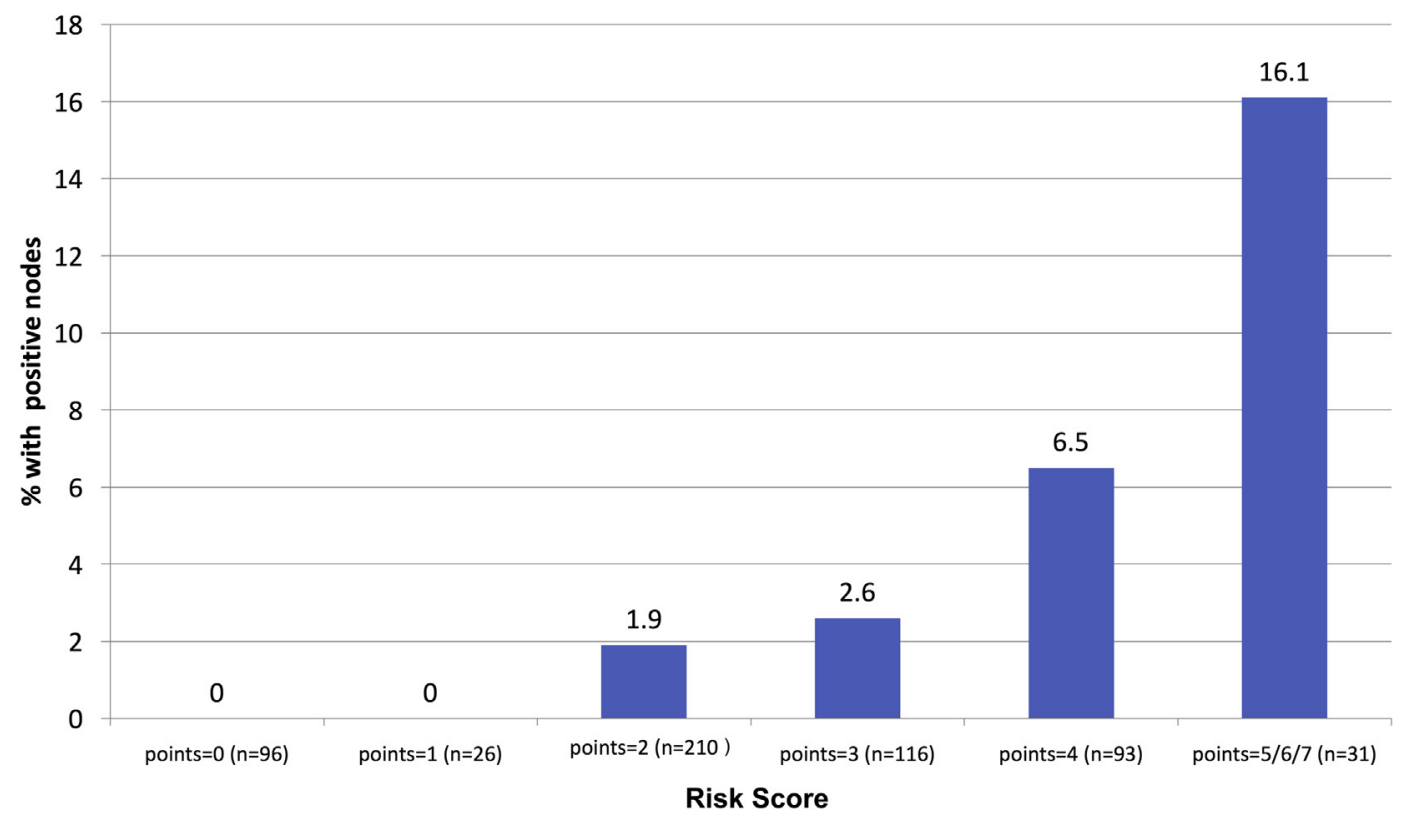

FIGURE 2. Percentage of T1a tumors with nodal metastases, plotted by risk score.

classified patients into different risk categories based on the following factors: $\mathrm{T} 1 \mathrm{a}$ or $\mathrm{T} 1 \mathrm{~b}$, low or high tumor grade, presence of LVI, and tumor size $2 \mathrm{~cm}$ or greater. They identified 6 risk categories that stratified the risk of nodal metastases: (1) T1a tumor with no other risk factors $(3.5 \%$ of nodal metastases); (2) T1a with 1 or more risk factor (6.7\% incidence of nodal metastases); (3) T1b with no other risk factors (7.4\% incidence of nodal metastases); (4) T1b tumors greater than $2 \mathrm{~cm}$ with no other risk factors (15.8\% incidence of nodal metastases); (5) $\mathrm{T} 1 \mathrm{~b}$ tumors with high-grade differentiation and no other risk factors (23\% incidence of nodal metastases); and (6) T1b tumors with 2 or more risk factors $(45 \%$ incidence of nodal metastases). Likewise, Barbour and colleagues ${ }^{15}$ retrospectively analyzed the records of 85 patients with T1 EAC and identified depth of tumor invasion, LVI, and poor differentiation

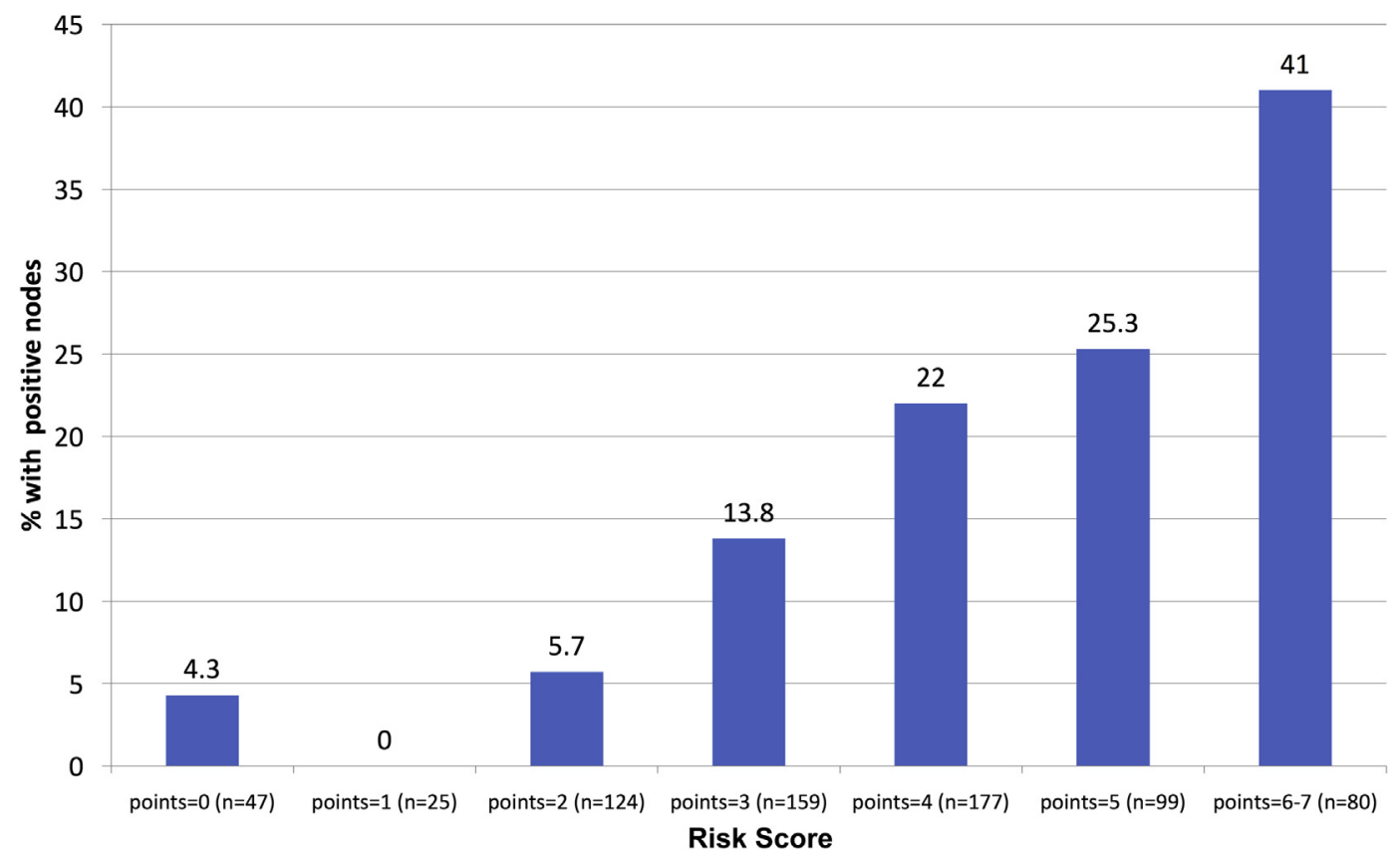

FIGURE 3. Percentage of T1b tumors with nodal metastases, plotted by risk score. 


\section{Using the National Cancer Database to Create a Scoring System that Identifies Patients with Early-Stage Esophageal Cancer at Risk for Nodal Metastases}

VIDEO 1. Significance and application of the present study. Video available at: http://www.jtcvsonline.org/article/S0022-5223(17)31578-7/fulltext.

as predictors of nodal metastases. They then stratified the patients into 4 risk groups: group I, T1a tumors $(0 \%$ incidence of nodal metastases); group II, T1b tumors, well/moderate differentiation, no LVI ( $4 \%$ incidence of nodal metastases); group III, T1b tumors, poor differentiation, no LVI (22\% incidence of nodal metastases); group IV, any T1b tumor with LVI ( $46 \%$ incidence of nodal metastases).These findings are consistent with the ability of our point-scoring system to predict the risk of nodal metastasis in patients with pT1a or pT1b EAC (Video 1).

\section{Study Limitations}

There are inherent limitations in the data from the NCDB. This is a retrospective study, and the data points cannot be verified. The tumor pathology cannot be reviewed for accuracy, and it is possible that some tumors may have been misclassified. In a relatively small study of 25 patients undergoing endoscopic resection of early esophageal cancer, there was a high rate of discordance $(48 \%)$ among pathologists in interpreting the depth of invasion. ${ }^{26}$ Most commonly, patients with T1a tumors were classified as $\mathrm{T} 1 \mathrm{~b}$, and this comprised $83 \%$ of all discordant cases. Another important shortcoming is the number of nodes harvested in the NCDB. In previous studies, the median number of lymph nodes harvested in the NCDB was only $10,{ }^{25}$ whereas current guidelines recommend that at least 15 nodes be harvested during surgery. ${ }^{27}$ Our study included

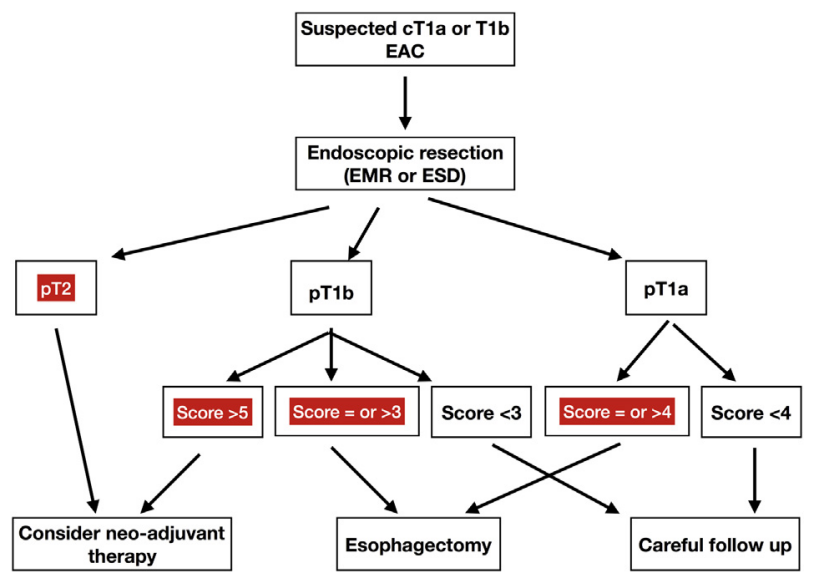

FIGURE 4. Suggested management algorithm for the management of patients with suspected early EAC. EAC, Esophageal adenocarcinoma; EMR, endoscopic mucosal resection; $E S D$, endoscopic submucosal dissection. only patients who underwent esophagectomy, which may introduce a selection bias, because during the study period endoscopic therapy was already being performed. This may have selected patients at a higher risk for nodal metastases than the general population of patients with T1 EAC. Finally, one of the most important factors predicting nodal metastases, LVI, was incorporated in the NCDB in 2010, and data on this factor are available for only 4 years. Although the variables we used to create the scoring system have been repeatedly shown to predict nodal metastases, our scoring system needs validation in other datasets, preferentially in prospective studies.

\section{CONCLUSIONS}

By using NCDB data, we constructed a simple scoring system that strongly predicts the risk of nodal metastases in patients with EAC. With this system, we identified a small group of patients with T1a tumors with a relatively high risk of nodal metastases and another small group of patients with T1b tumors with a low risk of nodal metastases. As in other scoring and risk stratification models, we identified a group of patients with $\mathrm{T} 1 \mathrm{~b}$ tumors with a very high risk of nodal metastases. We believe our scoring system can be incorporated into daily practice and will assist surgeons, gastroenterologists, and multidisciplinary tumor boards in deciding which patients should undergo esophagectomy and who could be observed after endoscopic resection. Of note, consideration should be given to preoperative neoadjuvant therapy to patients with $\mathrm{T} 1 \mathrm{~b}$ tumors with a very high risk of nodal metastases. We suggest a management algorithm for patients with suspected early esophageal carcinoma based on our score for risk stratification for nodal metastases (Figure 4).

\section{Conflict of Interest Statement}

B.W. is a proctor for Intuitive Surgery, consultant for Bard, and on the scientific advisory board for BioSix. All other authors have nothing to disclose with regard to commercial support.

The authors thank Shannon Wyszomierski, PhD, for expert scientific editorial review.

\footnotetext{
References

1. Leers JM, DeMeester SR, Oezcelik A, Klipfel N, Ayazi S, Abate E, et al. The prevalence of lymph node metastases in patients with T1 esophageal adenocarcinoma a retrospective review of esophagectomy specimens. Ann Surg. 2011;253: 271-8.

2. Gaur P, Sepesi B, Hofstetter WL, Correa AM, Bhutani MS, Vaporciyan AA, et al. A clinical nomogram predicting pathologic lymph node involvement in esophageal cancer patients. Ann Surg. 2010;252:611-7.

3. Liu L, Hofstetter WL, Rashid A, Swisher SG, Correa AM, Ajani JA, et al. Significance of the depth of tumor invasion and lymph node metastasis in superficially invasive (T1) esophageal adenocarcinoma. Am J Surg Pathol. 2005;29: 1079-85.

4. Boys JA, Worrell SG, Chandrasoma P, Vallone JG, Maru DM, Zhang L, et al. Can the risk of lymph node metastases be gauged in endoscopically resected
} 
submucosal esophageal adenocarcinomas? A Multi-Center Study. J Gastrointest Surg. 2016;20:6-12.

5. Lorenz D, Origer J, Pauthner M, Graupe F, Fisseler-Eckhoff A, Stolte M, et al. Prognostic risk factors of early esophageal adenocarcinomas. Ann Surg. 2014; 259:469-76.

6. Davison JM, Landau MS, Luketich JD, McGrath KM, Foxwell TJ, Landsittel DP, et al. A model based on pathologic features of superficial esophageal adenocarcinoma complements clinical node staging in determining risk of metastasis to lymph nodes. Clin Gastroenterol Hepatol. 2016;14:369-77.e363.

7. Bolton WD, Hofstetter WL, Francis AM, Correa AM, Ajani JA, Bhutani MS, et al. Impact of tumor length on long-term survival of pT1 esophageal adenocarcinoma. J Thorac Cardiovasc Surg. 2009;138:831-6.

8. Kauppi J, Gockel I, Rantanen T, Hansen T, Ristimaki A, Lang H, et al. Cause of death during long-term follow-up for superficial esophageal adenocarcinoma. Ann Surg Oncol. 2013;20:2428-33.

9. Pech O, Bollschweiler E, Manner H, Leers J, Ell C, Holscher AH. Comparison between endoscopic and surgical resection of mucosal esophageal adenocarcinoma in Barrett's esophagus at two high-volume centers. Ann Surg. 2011;254:67-72.

10. Manner H, Pech O, Heldmann Y, May A, Pohl J, Behrens A, et al. Efficacy, safety, and long-term results of endoscopic treatment for early stage adenocarcinoma of the esophagus with low-risk sm1 invasion. Clin Gastroenterol Hepatol. 2013;11: 630-5; quiz e645.

11. Young PE, Gentry AB, Acosta RD, Greenwald BD, Riddle M. Endoscopic ultrasound does not accurately stage early adenocarcinoma or high-grade dysplasia of the esophagus. Clin Gastroenterol Hepatol. 2010;8:1037-41.

12. Lin JL. T1 esophageal cancer, request an endoscopic mucosal resection (EMR) for in-depth review. J Thorac Dis. 2013;5:353-6.

13. Maish MS, DeMeester SR. Endoscopic mucosal resection as a staging technique to determine the depth of invasion of esophageal adenocarcinoma. Ann Thorac Surg. 2004;78:1777-82.

14. Lee L, Ronellenfitsch U, Hofstetter WL, Darling G, Gaiser T, Lippert C, et al. Predicting lymph node metastases in early esophageal adenocarcinoma using a simple scoring system. J Am Coll Surg. 2013;217:191-9.

15. Barbour AP, Jones M, Brown I, Gotley DC, Martin I, Thomas J, et al. Risk stratification for early esophageal adenocarcinoma: analysis of lymphatic spread and prognostic factors. Ann Surg Oncol. 2010;17:2494-502.

16. Bilimoria KY, Stewart AK, Winchester DP, Ko CY. The National Cancer Data Base: a powerful initiative to improve cancer care in the United States. Ann Surg Oncol. 2008;15:683-90.
17. Raghunathan TE, Solenberger PW. IVH, IVware: Imputation and Variance Estimation Software-User Guide. Ann Arbor, MI: University of Michigan; 2002.

18. Desquilbet L, Mariotti F. Dose-response analyses using restricted cubic spline functions in public health research. Stat Med. 2010;29:1037-57.

19. Ruopp MD, Perkins NJ, Whitcomb BW, Schisterman EF. Youden Index and optimal cut-point estimated from observations affected by a lower limit of detection. Biom J. 2008;50:419-30.

20. Sullivan LM, Massaro JM, D’Agostino RB Sr. Presentation of multivariate data for clinical use: The Framingham Study risk score functions. Stat Med. 2004;23: 1631-60.

21. Steyerberg EW, Harrell FE Jr, Borsboom GJ, Eijkemans MJ, Vergouwe Y, Habbema JD. Internal validation of predictive models: efficiency of some procedures for logistic regression analysis. J Clin Epidemiol. 2001;54: 774-81.

22. Pech O, May A, Manner H, Behrens A, Pohl J, Weferling M, et al. Long-term efficacy and safety of endoscopic resection for patients with mucosal adenocarcinoma of the esophagus. Gastroenterology. 2014;146:652-60.e651.

23. Badreddine RJ, Prasad GA, Lewis JT, Lutzke LS, Borkenhagen LS, Dunagan KT, et al. Depth of submucosal invasion does not predict lymph node metastasis and survival of patients with esophageal carcinoma. Clin Gastroenterol Hepatol. 2010;8:248-53.

24. Sepesi B, Watson TJ, Zhou D, Polomsky M, Litle VR, Jones CE, et al. Are endoscopic therapies appropriate for superficial submucosal esophageal adenocarcinoma? An analysis of esophagectomy specimens. J Am Coll Surg. 2010;210: 418-27.

25. Merkow RP, Bilimoria KY, Keswani RN, Chung J, Sherman KL, Knab LM, et al Treatment trends, risk of lymph node metastasis, and outcomes for localized esophageal cancer. J Natl Cancer Inst. 2014;106.

26. Worrell SG, Boys JA, Chandrasoma P, Vallone JG, Dunst CM, Johnson CS, et al Inter-observer variability in the interpretation of endoscopic mucosa resection specimens of esophageal adenocarcinoma. J Gastrointest Surg. 2016 20:140-5.

27. Ajani JA, D'Amico TA, Almhanna K, Bentrem DJ, Chao J, Das P, et al. Gastric Cancer, Version 3.2016, NCCN Clinical Practice Guidelines in Oncology. J Natl Compr Canc Netw. 2016;14:1286-312.

Key Words: esophageal cancer, early stage, esophagectomy, endoscopic therapy, nodal metastases 